\title{
Combined effects of the bisphosphonate, zoledronic acid and the aromatase inhibitor letrozole on breast cancer cells in vitro: evidence of synergistic interaction
}

\author{
HL Neville-Webbe ${ }^{*, I}$, RE Coleman' and I Holen' \\ 'Academic Unit of Clinical Oncology, Cancer Research Centre, Weston Park Hospital, Sheffield SIO 2SJ, UK
}

BACKGROUND: Aromatase inhibitors are widely used in the treatment of oestrogen receptor-positive post-menopausal breast cancer. These patients may also be receiving the bisphosphonate, zoledronic acid (ZA) to prevent bone loss or reduce skeletal morbidity in the setting of advanced disease. The potential biological interaction of these two drugs in breast cancer has not been assessed. METHODS: Aromatase-expressing breast cancer cells were treated with letrozole and ZA either simultaneously or in sequence, and the resulting apoptosis was assessed by staining with Hoechst 33342 and propidium iodide and examined using a fluorescent inverted Leica DMIRB microscope and a UV filter.

RESULTS: We found that letrozole and ZA induce levels of apoptosis in breast cancer cells in vitro that are significantly greater compared with treatment with each drug alone. However, this potentially, synergistic relationship is drug-sequence dependent, occurring only when cells are treated with letrozole, followed by ZA. The converse sequence, or administering drugs simultaneously, induces levels of apoptosis no greater than each drug alone.

CONCLUSION: Owing to the enhanced anti-tumour efficacy of sequential drug administration, our findings may indicate that, for post-menopausal women who require treatment with letrozole, ZA should also be considered.

British Journal of Cancer (2010) I 02, 1010-1017. doi:I0.1038/sj.bjc.6605579 www.bjcancer.com

Published online 16 February 2010

(C) 2010 Cancer Research UK

Keywords: zoledronic acid; letrozole; apoptosis; synergy; breast cancer

Letrozole is a non-steroidal third-generation aromatase inhibitor (AI) that binds to aromatase, which controls the last step in oestrogen synthesis. The AIs induce a profound reduction in oestradiol, oestrone and oestrone sulphate levels and, as a result, inhibit the growth of oestrogen-dependent breast cancer. In postmenopausal breast cancer, AIs are increasingly used in both metastatic (Mouridsen et al, 2001) and adjuvant settings (BIG1-98 Collaborators 2009; Goss et al, 2005).

Breast cancer patients may also require bisphosphonate, zoledronic acid (ZA) for various reasons. For example, letrozole (as with other AIs) causes bone loss and increases the risk of osteoporosis (Lester and Coleman, 2005). In addition, there is growing evidence for an adjuvant function for bisposphonates in early breast cancer (Gnant et al, 2009). Finally, patients may also be receiving $\mathrm{ZA}$ for metastatic bone disease, to reduce skeletal morbidity and pain (Rosen et al, 2001). As a result, increasing numbers of patients are receiving both $\mathrm{ZA}$ and letrozole in combination, either in early or advanced breast cancer. Table 1 lists current trials involving both ZA and letrozole in breast cancer that are either actively recruiting patients or closed to recruitment, but with results awaited.

\footnotetext{
*Correspondence: Dr HL Neville-Webbe;

E-mail: h.I.neville-webbe@sheffield.ac.uk

Received 6 October 2009; revised 25 January 20 I0; accepted 26 January

2010; published online 16 February 2010
}

The ZA is a potent nitrogen-containing bisphosphonate that inhibits osteoclastic bone resorption (Green et al, 1994). All nitrogen-containing bisphosphonates inhibit farnesyl pyrophosphate synthase in the mevalonate pathway (Dunford et al, 2001), leading to inhibition of farnesyl pyrophosphate and geranylgeranyl pyrophosphate. These isoprenoids are required for the post-translation lipid modification (i.e. farnesylation and geranylgeranylation) of signalling GTPases, such as Ras, Rho and Rac (Rogers et al, 2000). As these control a variety of important osteoclast cell functions, their loss ultimately leads to osteoclast apoptosis through caspase-3 enzyme activation (Benford et al, 2001).

In vitro, ZA also affects cancer cells directly through a wide variety of mechanisms. These include induction of apoptosis, inhibition of cancer cell growth, reduction of cancer cell adhesion, invasion and anti-angiogenic effects. Many of these anti-tumour effects are specifically related to inhibition of the mevalonate pathway, with potential for even greater anti-tumour activity when combined with other drugs (reviewed by Winter et al, 2008). To date, the interactions between ZA and letrozole on breast cancer cells in vitro have not been studied.

We have investigated whether ZA and letrozole, using cell culture conditions that mimic the post-menopausal state, have the potential for synergistic induction of apoptosis in breast cancer cells in vitro, and present novel insights into the interaction of $\mathrm{ZA}$ and the AI, letrozole. 
Table I Current trials involving zoledronic acid in conjunction with letrozole, actively recruiting or results awaited, in breast cancer patients

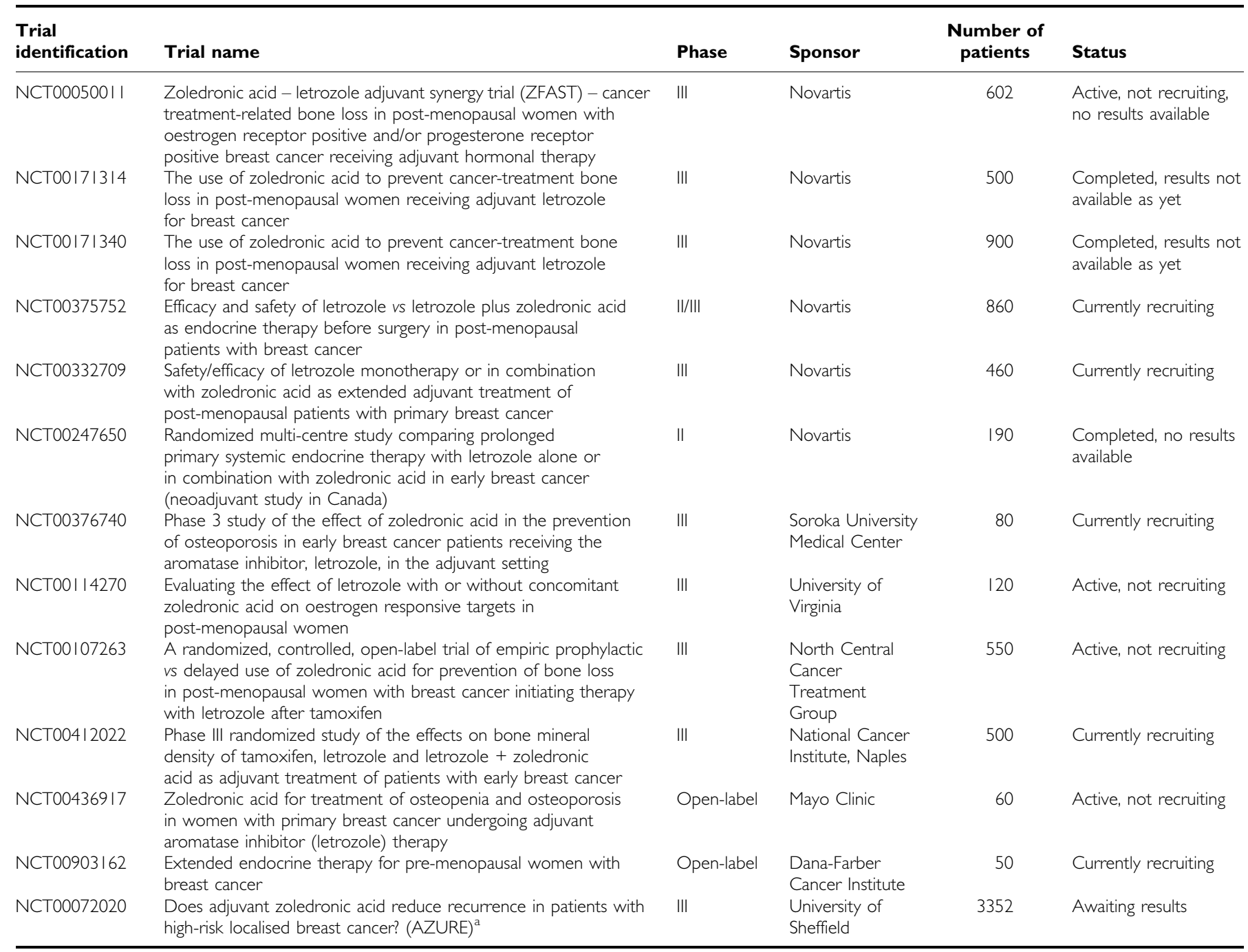

a Patients may be also receiving chemotherapy or other endocrine agents, not exclusively letrozole, with or without zoledronic acid. Sources: UK clinical trials gateway (http://www.controlled-trials.com) and Clinicaltrials.gov (http://www.clinicaltrials.gov.ct2/home).

\section{MATERIALS AND METHODS}

\section{Tissue culture}

To study the effect of letrozole in vitro, the human breast cancer cell line, MCF7-Ca, was used (provided by Dr S Chen New York, USA). This is an oestrogen receptor- and aromatase gene-expressing breast cancer cell line. For experiments using ZA alone, cells were routinely maintained in RPMI 1640 media, supplemented with $10 \%$ foetal calf serum (FCS), glutamine (2 mM) (all purchased from Gibco, Invitrogen Corporation, Paisley, UK), penicillin $\left(100 \mathrm{U} \mathrm{ml}^{-1}\right)$, streptomycin $\left(100 \mu \mathrm{g} \mathrm{ml}^{-1}\right)$ (both purchased from GlaxoSmithKline, Uxbridge, Middlesex, UK) and fungizone (Amphoteracin B) $\left(5 \mu \mathrm{g} \mathrm{ml}^{-1}\right)$ (Invitrogen Life Technologies Ltd, Paisley, Renfrewshire, UK).

To mimic post-menopausal oestrogen levels, it was necessary to deplete the medium of available oestrogen and add the aromatase substrate, androstenedione (AD). Under these conditions the only oestrogen available to cells would be through conversion of $\mathrm{AD}$ to oestrogen by the aromatase enzyme. Therefore, cells were grown and treated in phenol-red-free, glutamine-free RPMI 1640 media (purchased from Gibco, Invitrogen Corporation), supplemented with dextran-coated charcoal-stripped (from Sigma-Aldrich, Poole,
Dorset, UK) FCS. Phosphate-buffered solution (PBS) Dulbecco and trypsin-EDTA $(0.05 \%$ trypsin, $0.53 \mathrm{~mm}$ EDTA.4Na in Hanks-buffered saline solution) were supplied by Gibco (Invitrogen Corporation). All plastics were purchased from Costar Ltd (Bucks, UK).

\section{Drugs and chemicals}

The ZA ([1-hydroxy-2-(1H-imidazol-1-yl)ethylidene] bisphosphonic acid) was supplied as a disodium salt by Novartis (Basel, Switzerland). A stock solution $(10 \mathrm{~mm})$ was prepared in PBS and stored at $-20^{\circ} \mathrm{C}$. Letrozole was also a gift from Novartis and supplied as a dry powder that was reconstituted in $100 \%$ ethanol to make a $0.1 \mathrm{M}$ stock solution, and stored at $4-8^{\circ} \mathrm{C}$. The stock solution of each drug was diluted in appropriate culture media and sterile filtered before use.

Geranylgeraniol (GGOH) (all trans-3, 7,11-15-tetramethyl-2, 6,10,14-hexadecatetraen-1-ol) and 4-androsten-3, 17-dione (AD) were purchased from Sigma-Aldrich. Geranylgeraniol was diluted in ethanol ( $1 \mathrm{M}$ stock solution) and stored at $-20^{\circ} \mathrm{C}$. For use in experiments, it was diluted at least 20000 -fold with culture media. Androstenedione was supplied as $1 \mathrm{mg}$ dry powder, which was serially diluted in ethanol. A concentration of $25 \mathrm{~nm}$ was used for 
experiments on the basis of an earlier study by Professor A Brodie (Thiantanawat et al, 2003).

\section{Treatment of cells}

Cells were seeded (at $20000 / 0.5 \mathrm{ml}$ per well) in 24 -well plates and incubated for 3 days (to confluence) before treatment. On the day of treatment, cells were washed using $0.5 \mathrm{ml}$ of sterile PBS, and an appropriate culture medium containing the $\operatorname{drug}(\mathrm{s})$ of interest was added to the wells.

\section{Proliferation assay}

Cells (MCF7-Ca) were seeded in 24-well plates and treated with either letrozole $(0-100 \mathrm{nM})$ or ZA $(0-25 \mu \mathrm{M})$, and at the end of each specified incubation period, cells were counted using a Coulter counter (Beckman Coulter, $\mathrm{Z}$ series).

\section{Apoptosis assay}

At the end of the specified drug treatment period, cells were stained with $8 \mu \mathrm{M}$ Hoechst 33342 (Sigma RBI, Poole, Dorset, UK) and $5 \mu \mathrm{M}$ propidium iodide (Molecular Probes, Cambridge Biochemical, Cambridge, UK) for $15 \mathrm{~min}$ at $37^{\circ} \mathrm{C}$. Both attached and detached cells were stained and examined using a fluorescent inverted Leica DMIRB microscope and a UV filter $(355 \mathrm{~nm}$ excitation and $465 \mathrm{~nm}$ emission). Propidium iodide was excluded by viable cells, but stained the nuclei of necrotic cells. Hoechst 33342 entered the nuclei of viable and apoptotic cells, the latter being recognised by characteristic features of karyorrhexis. The incidence of viable, apoptotic and necrotic cells was obtained by counting using a Whipple graticule in five separate random grid areas in each of three wells for each treatment.

\section{Experiments involving sequential administration of $\mathrm{ZA}$ and letrozole}

For these experiments, MCF7-Ca cells were seeded in 24-well plates, and cells were treated with ZA $(10 \mu \mathrm{M})$ and letrozole $(100 \mathrm{nM})$, each for $24 \mathrm{~h}$, alone and in combination, in oestrogenfree media supplemented with $\mathrm{AD}(25 \mathrm{nM})$, as follows (Figure 1 indicates the experiment design):

Group 1, 'letrozole followed by ZA': Cells were initially treated with letrozole on day 1 , and after $24 \mathrm{~h}$ incubation (day 2), the cells were washed and then treated with ZA for $24 \mathrm{~h}$ until day 3 . At the end of $24 \mathrm{~h}$ incubation with $\mathrm{ZA}$, the cells were again washed and incubated in fresh media (FM) for a further $24 \mathrm{~h}$, with cells being assessed for apoptosis and necrosis on day 4 .

Group 2, 'ZA followed by letrozole': Cells were initially treated with $\mathrm{ZA}$ on day 1 , and after $24 \mathrm{~h}$ incubation (day 2), they were
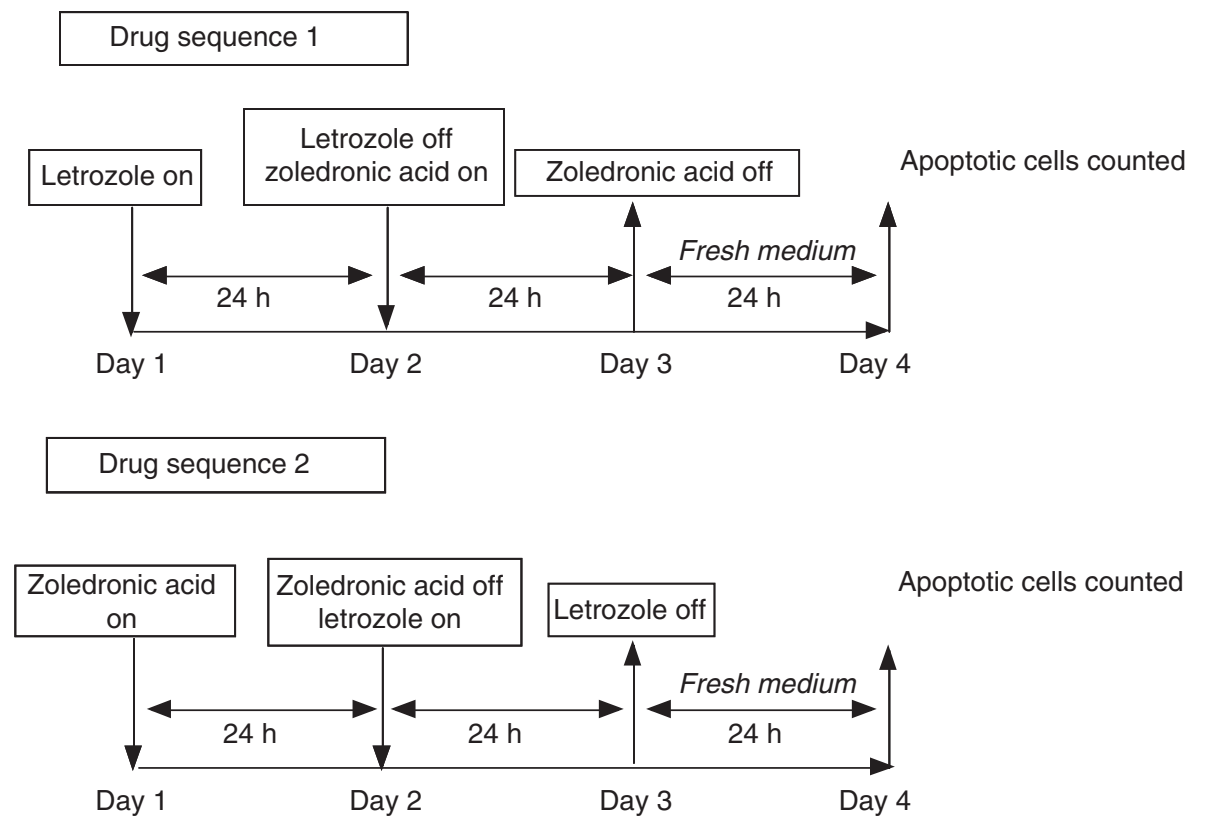

\section{Drug sequence 3}

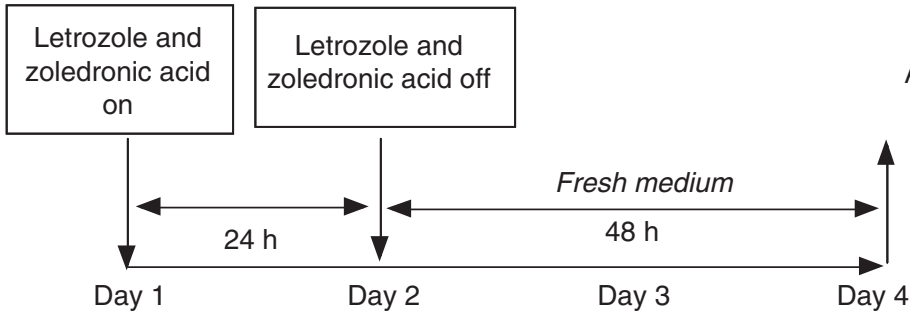

Figure I Experiment design for investigating the effects of sequential treatment of MCF7-Ca cells with letrozole (I $00 \mathrm{~nm})$ and zoledronic acid ( $25 \mu \mathrm{M})$. Drug sequence I: 'letrozole followed by zoledronic acid'; drug sequence 2: 'zoledronic acid followed by letrozole'; drug sequence 3: 'zoledronic acid and letrozole together'). 
washed and treated with letrozole for $24 \mathrm{~h}$ until day 3 . At the end of $24 \mathrm{~h}$ incubation with letrozole, the cells were again washed and incubated in FM for a further $24 \mathrm{~h}$, with cells being assessed for apoptosis and necrosis on day 4.

Group 3, 'ZA and letrozole together': Cells were treated with $\mathrm{ZA}$ and letrozole, both administered together on day 1 . After $24 \mathrm{~h}$ (day 2), cells were washed and further incubated in FM until day 4.

Control groups: Cells were treated with negative and positive controls as follows:

with FM alone (days $1-4$ );

with ZA (days 1 and 2, added and removed at the same time as $\mathrm{ZA}$ in group 2 or 3 , and 1, respectively, and cells further incubated in FM until day 4);

with letrozole (days 1 and 2, added and removed at the same time as letrozole in group 1 or 3, and 2, respectively, and cells further incubated in FM until day 4).

In all groups, cells were assessed for levels of viable, apoptotic and necrotic cells on day 4 , as detailed in the above section.

\section{Statistical analysis}

Statistical analysis was performed using SPSS 11 for Mac OS X. For analysis of differences between means, one-way analysis of variance or the Kruskal-Wallis test for non-parametric data was used. Post hoc analysis was carried out using Tukey's HSD, Dunnett's or the Games-Howell test, as appropriate. For non-parametric data, post hoc analysis was performed using the Mann-Whitney $U$-test, with a Bonferroni correction applied. All experiments were repeated at least three times, and graphs represent the mean of combined experiments with bars representing the s.e.m., unless otherwise indicated.

\section{RESULTS}

Effect of letrozole on the growth and survival of MCF7-Ca breast cancer cells

The MCF7-Ca cells were grown and treated with letrozole $(0-100 \mathrm{nM})$ for up to $72 \mathrm{~h}$ in oestrogen-depleted media with addition of AD. Only after $72 \mathrm{~h}$ of treatment was there a significant growth inhibition with $100 \mathrm{~nm}(P=0.001 v s$ control), whereas 24 and $48 \mathrm{~h}$ of treatment with letrozole did not significantly inhibit cell growth (Figure 2). Treatment of cells with letrozole for $72 \mathrm{~h}$, however, resulted in a significant dose-dependent increase in the percentage of apoptosis $(P<0.0001)$ (Figure 2). A volume of 10 and $100 \mathrm{~nm}$ of letrozole induced 10.7 and $18.1 \%$ apoptosis compared with control levels of $7 \%(P=0.47$ and $P<0.001$, respectively). It is interesting that, even with the highest concentration of letrozole, the levels of necrosis were not significantly greater than those in control samples, indicating that the mode of induced cell death of letrozole under these conditions is apoptosis (Figure 3 ).

\section{Effect of ZA on growth and survival of MCF7-Ca breast cancer cells}

In contrast to the growth-inhibitory effect of letrozole on MCF7-Ca cells, exposing the cells to ZA $(0-25 \mu \mathrm{M})$ for only $1 \mathrm{~h}$ induced significant growth inhibition with as little as $1 \mu \mathrm{M}$ of ZA. This caused a $35.8 \%$ reduction in cell proliferation, compared with that in control $(P=0.0025)$. A similar growth-inhibitory effect was obtained with $10 \mu \mathrm{M}(37.2 \%$ reduction in proliferation, $P=0.03)$ and $25 \mu \mathrm{M}(5.2 \%$ reduction in proliferation, $P=0.005)$ (Figure 4$)$.

To investigate the apoptosis-inducing effects of ZA, initial experiments investigated the effect of ZA $(0-25 \mu \mathrm{M})$ treatment of MCF7-Ca cells for $72 \mathrm{~h}$ continuously. This induced a significant concentration-dependent increase in apoptosis and necrosis, with a maximal level of $21.4 \%(P<0.01)$ and $39.3 \% \quad(P<0.01)$, respectively, with $25 \mu \mathrm{M}$ (Figure $5 \mathrm{~A}$ ). Concentrations of at least

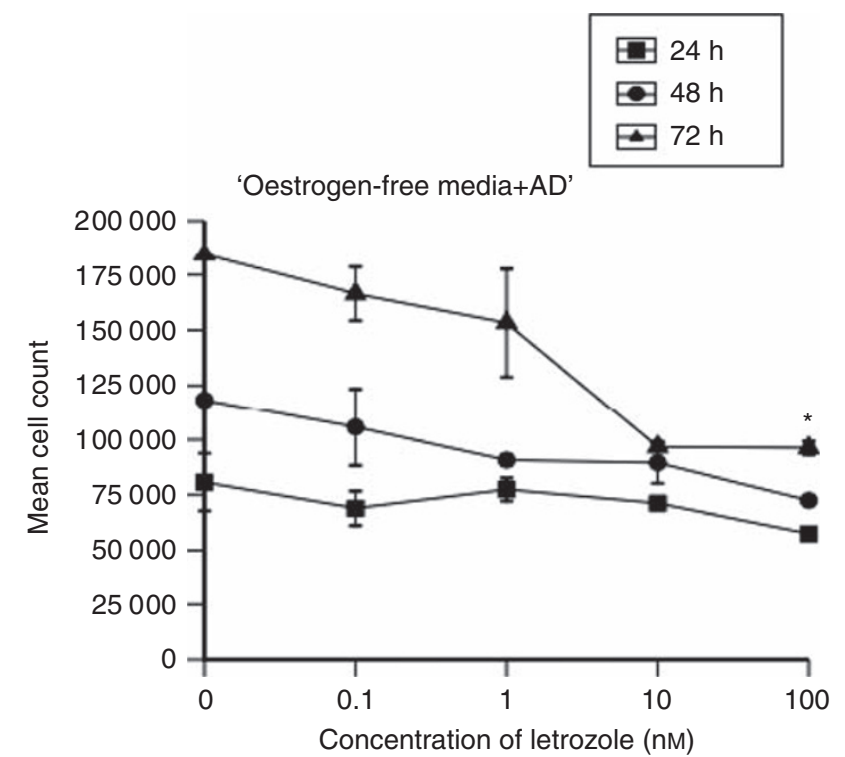

Figure 2 Growth inhibition of MCF7-Ca cells treated with letrozole $(0-100 \mathrm{nM})$ for $24-72 \mathrm{~h}(* P=0.001$ vs control).

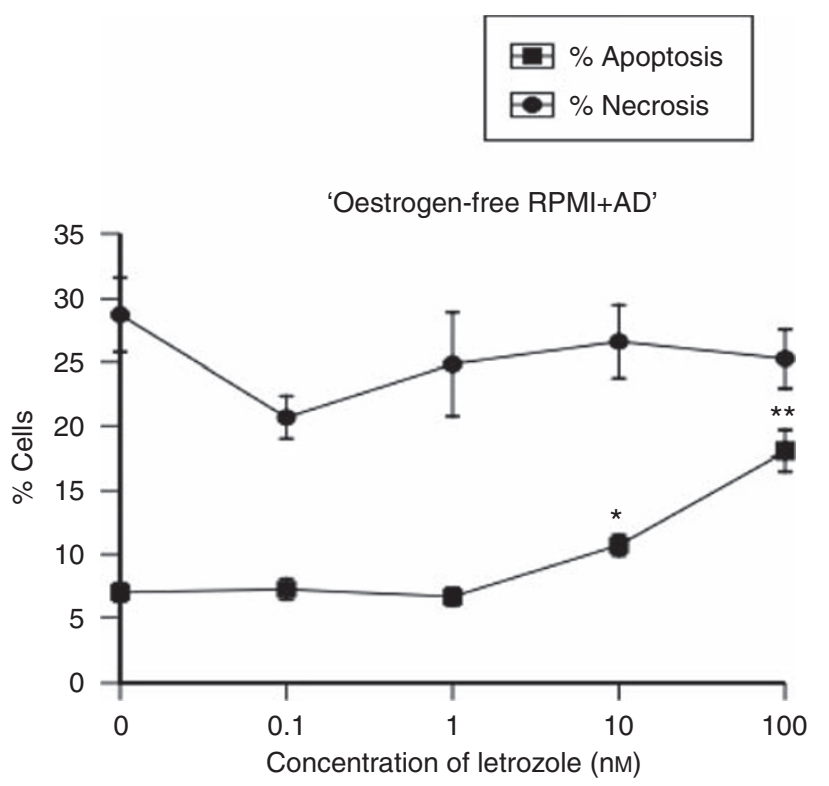

Figure 3 Induction of apoptosis vs necrosis in MCF7-Ca cells after treatment with letrozole $(0-100 \mathrm{~nm})$ for $72 \mathrm{~h}$ continuously in oestrogenfree media ( $* P<0.05$ and $* * P<0.001$ vs control).

$1 \mu \mathrm{M}$ of ZA induced a significant increase in apoptosis compared with control, whereas a concentration of at least $10 \mu \mathrm{M}$ was required to induce significant necrosis.

After a standard $4 \mathrm{mg}$ infusion of $\mathrm{ZA}$, serum concentrations rapidly fall within $1-2 \mathrm{~h}$ as the drug localises to the bone (Chen et al, 2002). When MCF7-Ca cells were treated with ZA $(0-25 \mu \mathrm{M})$ for $1 \mathrm{~h}$, followed by a $72 \mathrm{~h}$ incubation in FM, there was still a concentration-dependent increase in apoptosis, compared with control. Apoptosis that was significantly greater compared with that in untreated controls occurred with at least $1 \mu \mathrm{m}$. The maximal apoptosis induced was $3.6 \%$ with $25 \mu \mathrm{M}$ of $\mathrm{ZA}(P<0.001$, compared with control). Significantly increased levels of necrosis were only caused by the highest concentration of ZA $(25 \mu \mathrm{M})(4.7 v s 2 \%$ in control, $P=0.011$ ) (Figure 5B). 
Collectively, these results indicate that MCF7-Ca cells are sensitive to the apoptosis-inducing effects of ZA, even when used for a short period of $1 \mathrm{~h}$. When extending the incubation period,

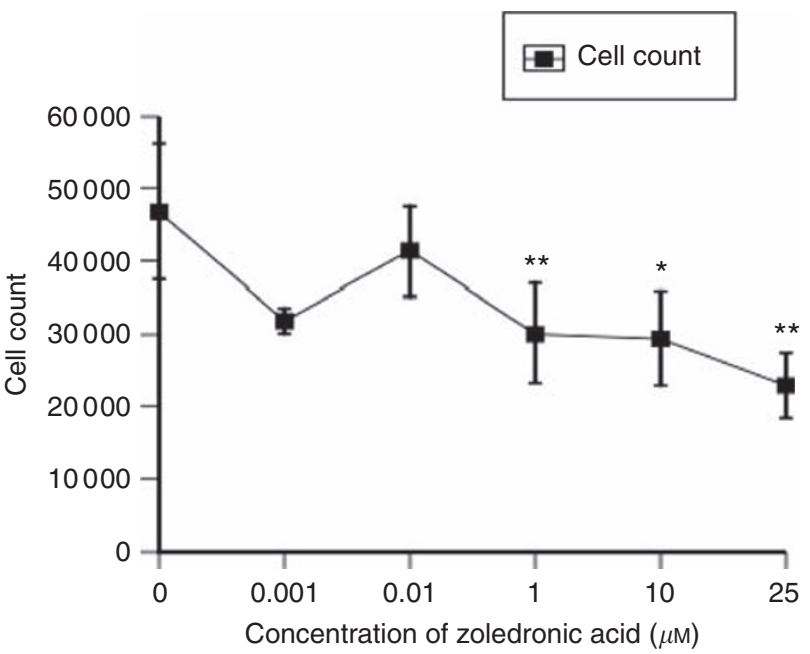

Figure 4 Growth inhibition of MCF7-Ca cells treated with zoledronic acid $(0-25 \mu \mathrm{M})$ for I $\mathrm{h}(* P<0.05$ and $* * P<0.0$ I compared with untreated controls). there is a significant increase in the levels of apoptosis, but with an accompanying increase in necrotic cell death.

\section{Effect of sequential ZA and letrozole on induction of MCF7-Ca breast cancer cell apoptosis}

We next investigated the combined effects of ZA and letrozole on MCF7-Ca cells, and whether drug sequencing had any effect on the levels of apoptosis. For these experiments, MCF7-Ca cells were treated with ZA $(10 \mu \mathrm{M})$ and letrozole $(100 \mathrm{~nm})$, each for $24 \mathrm{~h}$, alone and in combination, in oestrogen-free media supplemented with $\mathrm{AD}(25 \mathrm{~nm})$, as explained in the 'Materials and Methods' section.

As shown in Figure 6, increased levels of apoptosis occurred when cells were treated with letrozole and ZA. However, this was sequence dependent. Treating cells with letrozole, followed by ZA, induced a level of apoptosis that was eight times greater than treatment with letrozole alone $(3.2$ vs $0.4 \%, P<0.001)$ and nearly five times greater than that with $\mathrm{ZA}$ alone $(3.2$ vs $0.7 \%, P<0.001)$ (Figure 6A). However, treating cells with $\mathrm{ZA}$, followed by letrozole, induced only a total of $0.8 \%$ apoptosis, which was not significantly greater than treatment with either drug alone (Figure 6B). Similarly, treating cells simultaneously with ZA and letrozole together induced only $0.4 \%$ apoptosis, again not significantly greater than that with either drug alone (Figure 6C).

Finally, the sequence 'letrozole then ZA' induced significantly more apoptosis than either the sequence ' $\mathrm{ZA}$ then letrozole' $(P<0.001)$ or the sequence 'ZA plus letrozole' $(P<0.001)$. In all
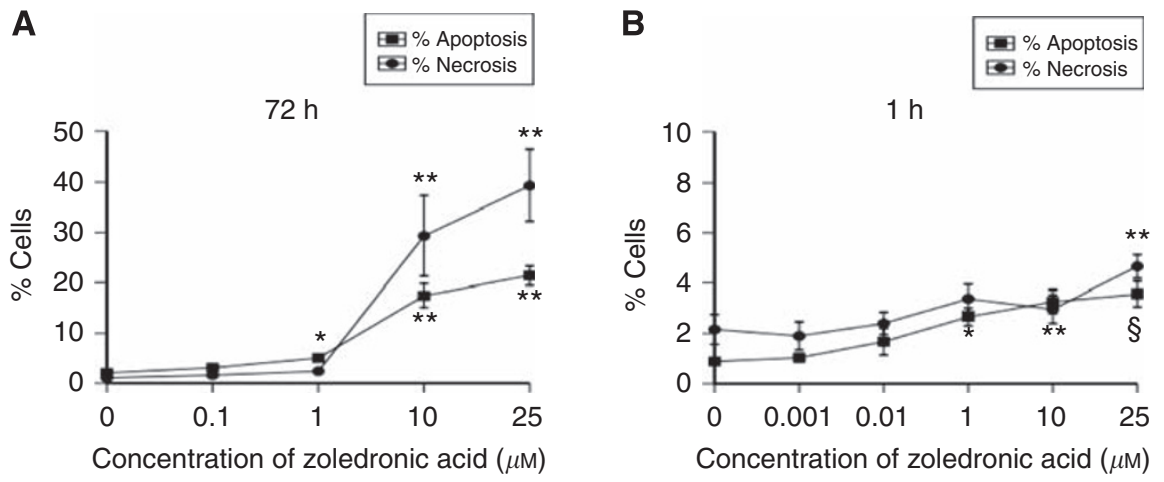

Figure 5 (A) Induction of apoptosis vs necrosis in MCF7-Ca cells after treatment with zoledronic acid $(0-25 \mu \mathrm{M})$ for $72 \mathrm{~h}$ continuously $(* P<0.05$ and $* * P<0.0$ I vs control). (B) Induction of apoptosis vs necrosis in MCF7-Ca cells after treatment with zoledronic acid $(0-25 \mu \mathrm{M})$ for I h $(* P<0.05$, $* * P \leqslant 0.0$ I and ${ }^{\S} P<0.001$, compared with untreated controls).

A

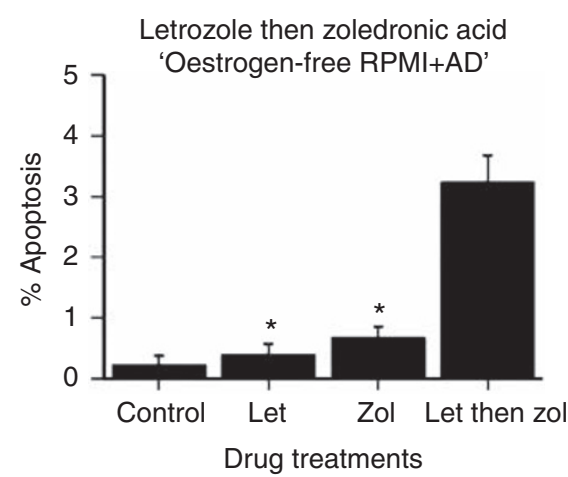

B

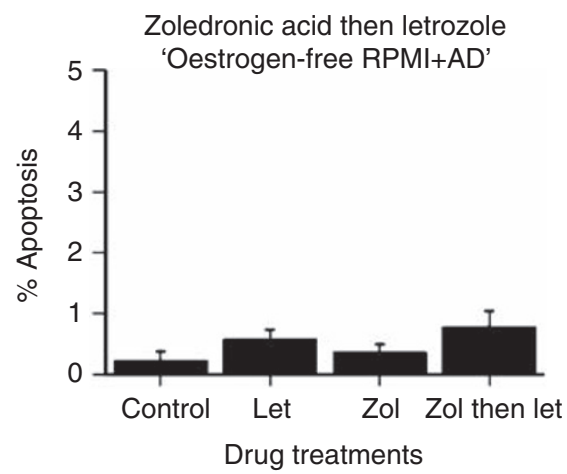

C

$\%$ Apoptosis

Together

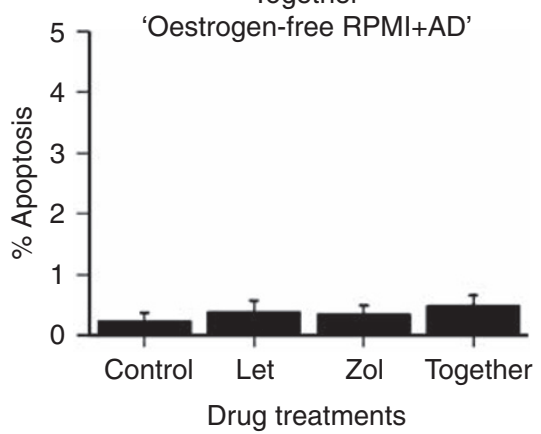

Figure 6 The effect of drug sequencing with 'letrozole followed by ZA' (A), 'ZA followed by letrozole' (B) and 'ZA and letrozole together' (C) on resultant apoptosis when MCF7-Ca cells are treated with letrozole (I00 nM) and zoledronic acid (I0 $\mu \mathrm{M})$, each for $24 \mathrm{~h}$ in oestrogen-free media plus AD ( ${ }^{*} P<0.00 \mathrm{I}$, compared with the drugs in combination). 


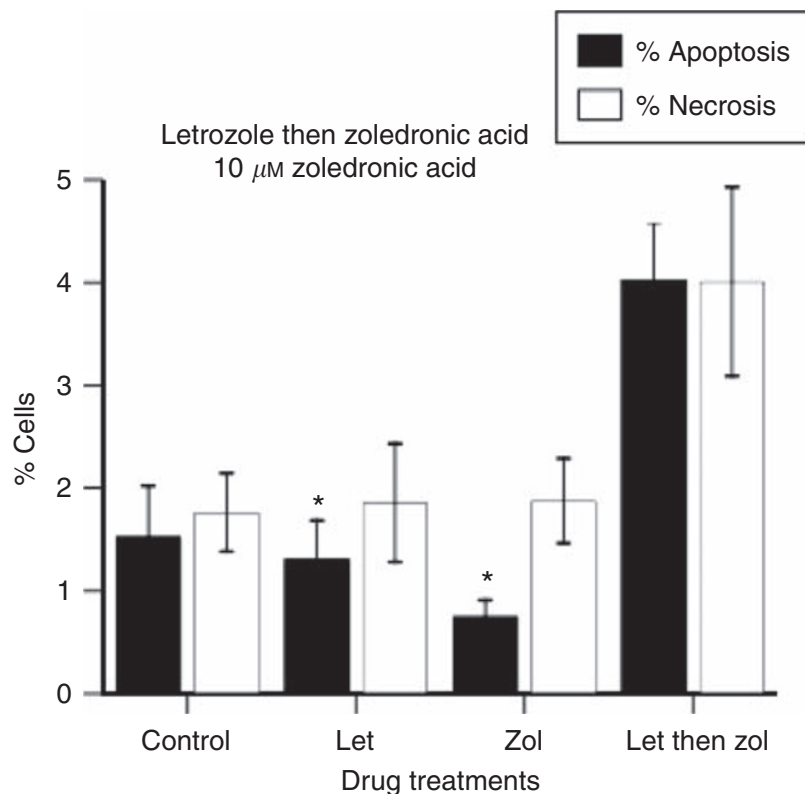

Figure 7 The effect of drug sequencing with letrozole followed by ZA on apoptosis when a clinically relevant concentration of ZA is used (*P $<0.0$ I for letrozole followed by ZA vs each drug alone).

three treatment groups ('letrozole then ZA', 'ZA then letrozole' and ' $\mathrm{ZA}$ and letrozole together'), the levels of necrosis were not significantly different compared with those in untreated controls.

In summary, these results indicate that when MCF7-Ca cells are treated with letrozole and $\mathrm{ZA}$ in combination, only treating cells sequentially with letrozole followed by ZA induces substantially increased levels of apoptosis suggestive of synergy.

\section{Effects of low, clinically relevant concentrations of ZA}

As discussed earlier, ZA leaves the circulation rapidly after intravenous infusion to localise to the bone, with plasma peak levels of around $1 \mu \mathrm{M}$ for $1 \mathrm{~h}$ (Chen et al, 2002). Consequently, having established that there is potential for enhanced levels of apoptosis when breast cancer cells are treated with letrozole followed by ZA, it was of interest to determine whether this effect could be achieved using a concentration of ZA that more accurately reflects peak circulating levels.

For initial experiments, MCF7-Ca cells were treated with letrozole $(100 \mathrm{nM}$ for $24 \mathrm{~h})$, and thereafter with $10 \mu \mathrm{M}$ of $\mathrm{ZA}$ for $1 \mathrm{~h}$ only. We found that the resultant levels of apoptosis with sequential treatment was five times greater than that with $\mathrm{ZA}$ alone ( 4.0 vs $0.8 \%, P=0.001)$, and three times greater than treatment with letrozole alone (4.0 vs $1.3 \%, P=0.01)$ (Figure 7). However, when the concentration of $\mathrm{ZA}$ was further reduced to $1 \mu \mathrm{M}$, treating MCF7-Ca cells with letrozole ( $100 \mathrm{~nm}$ for $24 \mathrm{~h}$ ) followed by $1 \mu \mathrm{M} \mathrm{ZA}$ for $1 \mathrm{~h}$, the effect of enhanced apoptosis was not observed, with the resultant apoptosis being $1.3 \%$ and necrosis being $1.7 \%$. In neither case was this significantly greater than treatment with each drug alone (data not shown). These results suggest a potentially synergistic relationship. Though not reproducible using a very low concentration of ZA, synergy is induced with $10 \mu \mathrm{M}$, a concentration that could be achieved within the bone microenvironment.

\section{Function of the mevalonate pathway on ZA- and letrozole-induced apoptosis}

To assess whether increased levels of apoptosis induced by ZA and letrozole in combination is, at least in part, due to inhibition of the mevalonate pathway by ZA, the effect of the addition of GGOH was investigated. Geranylgeraniol is a distal component of the mevalonate pathway. If the mechanism of induced apoptosis is through inhibition of this pathway, we would expect the levels of apoptosis to be restored when GGOH is added to cells being treated with ZA and letrozole. Cells (MCF7-Ca) were treated with letrozole $(100 \mathrm{nM}, 24 \mathrm{~h})$, and thereafter with $\mathrm{ZA}(10 \mu \mathrm{M}, 1 \mathrm{~h}$, with or without $50 \mu \mathrm{M} \mathrm{GGOH}$, added and removed simultaneously with ZA).

For cells treated with letrozole followed by ZA, the resultant apoptosis was $4.0 \%$, a level that was significantly greater than that caused by letrozole alone $(1.3 \%, P=0.011), \mathrm{ZA}$ alone $(0.8 \%$, $P=0.001)$ or $\mathrm{GGOH}$ alone $(0.3 \%, P<0.001)$ (Figure 8$)$. The addition of $\mathrm{GGOH}$ to cells treated with letrozole followed by ZA reduced levels of apoptosis by $50 \%$ ( $2 \%$ with GGOH vs $4 \%$ without, $P=0.05$ ).

These results indicate that the increased level of apoptosis obtained when cells are treated with letrozole followed by ZA is, in part, through inhibition of the mevalonate pathway, as a component of this pathway, GGOH, restores levels of apoptosis by up to $50 \%$.

\section{DISCUSSION}

We have evaluated the in vitro effects of different doses of letrozole and ZA, alone and in combination, on MCF7-Ca cell proliferation and apoptosis. As a single agent, letrozole alone significantly inhibited the growth of cells only after $72 \mathrm{~h}$ incubation with the highest tested concentration (100 nM). This suggests that growth inhibition by letrozole in vitro is not as important as the effects on apoptosis, as $100 \mathrm{~nm}$ of letrozole induced up to $18 \%$ apoptosis.

The ZA effectively inhibited the growth of these cells. Even just $1 \mathrm{~h}$ of treatment (followed by a drug-free incubation period) caused significant growth inhibition, with concentrations as low as $1 \mu \mathrm{M}$. However, to detect this inhibitory effect, cells were incubated in fresh medium for up to $72 \mathrm{~h}$ after exposure to the drug. This period is required for a turnover of (already) prenylated proteins 
before inhibition of the mevalonate pathway by ZA (Neville-Webbe et al, 2005) and subsequent apoptosis.

In combination, ZA and letrozole have potential for synergistic induction of MCF7-Ca cells in vitro. However, increased induction of apoptosis only occurred when cells were treated with letrozole followed by ZA. 'Letrozole then ZA' induced a level of apoptosis that was over eight times greater than that caused by letrozole alone, and 4.8 times greater than treatment with $\mathrm{ZA}$ alone.

The ZA has consistently shown potential for synergistic interaction with drugs commonly used in breast cancer. This includes a combination with paclitaxel (Jagdev et al, 2001; Neville-Webbe et al, 2006), tamoxifen (Jagdev et al, 2000) and doxorubicin (Neville-Webbe et al, 2005). In our earlier study with ZA and chemotherapy drugs, we have similarly found that sequential administration of drugs is of paramount importance for inducing maximal (potentially synergistic) levels of apoptosis. For breast cancer cells treated with ZA in combination with either doxorubicin or paclitaxel, as with letrozole, cells had to be treated with the chemotherapy drug first, and thereafter with ZA. Treating cancer cells with the reverse sequence, or even simultaneously, was either antagonistic or, at best, additive, and the same patterns were seen here with letrozole. Our group recently evaluated this sequence-dependent synergy in an in vivo soft-tissue breast tumour model (Ottewell et al, 2008a, b). Using clinically relevant doses of doxorubicin and ZA, inhibition of tumour growth was shown to be sequence dependent with doxorubicin followed by ZA, leading to inhibition of tumour growth associated with evidence of enhanced tumour cell apoptosis and reduced proliferation.

The biological effects of letrozole and ZA are largely mediated through the induction of apoptosis. It is likely that this is enhanced through inhibition of the mevalonate pathway. Using an intermediary of this pathway (GGOH), apoptosis was reduced by $50 \%$ for cells treated with the sequence ' letrozole then ZA'. Inhibition of the mevalonate pathway by nitrogen-bisphosphonates is integral for inducing a variety of effects including apoptosis of osteoclasts (Amin et al, 1992), breast cancer cells (Jagdev et al, 2001), prostate cancer cells (Oades et al, 2003), myeloma cells (Shipman et al, 1998) and inhibition of tumour cell invasion (Denoyelle et al, 2003). Furthermore, inhibition of this pathway also contributes to the apoptosis induced when breast (and prostate) cancer cells are treated in combination with ZA and doxorubicin (Neville-Webbe et al, 2005), or when breast cancer cells are treated with ZA and paclitaxel (Neville-Webbe et al, 2006).

Although in vitro and in vivo studies have limited implications for the clinical setting, it is interesting to note a recent update of the ZO-FAST study (Eidtmann et al, 2008). This clinical trial assesses the effects of ZA on letrozole-induced bone loss in postmenopausal women with early breast cancer. Patients are randomised to either combined letrozole and ZA (4 mg every 6 months) or letrozole alone. A recent update, with a 36-month follow-up, suggested a better outcome for those treated with the combination, with a $41 \%$ risk reduction in cancer recurrence. Although these results are preliminary, and the trial was not specifically set up to address the anti-tumour potential of ZA in patients receiving letrozole, they add to the growing evidence of the direct anti-cancer effects of this bisphosphonate in combination with other drugs, including endocrine treatments. Similarly, in the ABCSG 12 trial of pre-menopausal breast cancer patients (Gnant et al, 2009), 1803 patients received ovarian suppression with goserelin and were then randomised to receive either tamoxifen or the AI anastrazole, with or without ZA (4 mg infusions every 6 months for 3 years). No significant differences in disease-free survival were seen between tamoxifen and AI. However, the group receiving ZA had a statistically significant $36 \%$ reduction in the risk of disease recurrence, compared with patients receiving endocrine therapy alone $(P=0.01)$. The reduction in metastatic events was not confined to a reduction in the frequency of bone metastases alone, but also applied to distant metastatic sites, loco-regional recurrence rates and cancer of contralateral breast. Reduction of metastases outside the skeleton adds to the growing evidence that the antitumour effects of ZA are not confined to the bone, and such antitumour effects may be enhanced by combination with other drugs.

In summary, letrozole has anti-tumour activity (which is largely through induction of apoptosis) when used alone under culturemedia conditions that mimic the post-menopausal state. When combined with ZA, there is potential for a synergistic induction of apoptosis, but only when cancer cells are treated with letrozole followed by ZA. This may have positive implications for postmenopausal patients receiving both these drugs in the clinical setting.

\section{REFERENCES}

Amin D, Cornell SA, Gustafson SK, Needle SJ, Ullrich JW, Bilder GE Perrone MH (1992) Bisphosphonates used for the treatment of bone disorders inhibit squalene synthase and cholesterol biosynthesis. J Lipid Res 33: $1657-1663$

Benford HL, McGowan NW, Helfrich MH, Nuttall ME, Rogers MJ (2001) Visualization of bisphosphonate-induced caspase-3 activity in apoptotic osteoclasts in vitro. Bone 28: $465-473$

Chen T, Berenson J, Vescio R, Swift R, Gilchick A, Goodin S, LoRusso P, Ma P, Ravera C, Deckert F, Schran H, Seaman J, Skerjanec A (2002) Pharmacokinetics and pharmacodynamics of zoledronic acid in cancer patients with bone metastases. J Clin Pharmacol 42: 1228-1236

Denoyelle C, Hong L, Vannier JP, Soria J, Soria C (2003) New insights into the actions of bisphosphonate zoledronic acid in breast cancer cells by dual RhoA-dependent and -independent effects. $\mathrm{Br}$ J Cancer 88: $1631-1640$

Dunford JE, Thompson K, Coxon FP, Luckman SP, Hahn FM, Poulter CD, Ebetino FH, Rogers MJ (2001) Structure-activity relationships for inhibition of farnesyl diphosphate synthase in vitro and inhibition of bone resorption in vivo by nitrogen-containing bisphosphonates. J Pharmacol Exp Ther 296: 235-242

Eidtmann H, Bundred N, Deboer R, Llombart A, Davidson N, Neven P, von Minckwitz G, Miller J, Schenk N, Coleman R (2008) The effect of zoledronic acid on aromatase inhibitor associated bone loss in postmenopausal women with early breast cancer receiving adjuvant letrozole: 36 months follow-up of ZO-FAST. CTRC-AACR San Antonio Breast Cancer Symposium 69: Abstract 44

Gnant M, Mlineritsch B, Schippinger W, Luschin-Ebengreuth G, Postlberger S, Menzel C, Jakesz R, Seifert M, Hubalek M, Bjelic-Radisic V, Samonigg H, Tausch C, Eidtmann H, Steger G, Kwasny W, Dubsky P, Fridrik M, Fitzal F, Stierer M, Rucklinger E, Greil R, March C (2009) Endocrine therapy plus zoledronic acid in premenopausal breast cancer. N Engl J Med 360: 679-691

Goss PE, Ingle JN, Martino S, Robert NJ, Muss HB, Piccart MJ, Castiglione M, $\mathrm{Tu}$ D, Shepherd LE, Pritchard KI, Livingston RB, Davidson NE, Norton L, Perez EA, Abrams JS, Cameron DA, Palmer MJ, Pater JL (2005) Randomized trial of letrozole following tamoxifen as extended adjuvant therapy in receptor-positive breast cancer: updated findings from NCIC CTG MA.17. J Natl Cancer Inst 97: 1262-1271

Green JR, Muller K, Jaeggi KA (1994) Preclinical pharmacology of CGP $42^{\prime} 446$, a new, potent, heterocyclic bisphosphonate compound. J Bone Miner Res 9: $745-751$

Jagdev SP, Coleman RE, Shipman CM, Rostami HA, Croucher PI (2001) The bisphosphonate, zoledronic acid, induces apoptosis of breast cancer cells: evidence for synergy with paclitaxel. Br J Cancer 84: 1126-1134

Jagdev SP, Croucher P, Coleman RE (2000) Zoledronate induces apoptosis of breast cancer cells in vitro-evidence for additive and synergistic effects with taxol and tamoxifen. Proceedings of American Society of Clinical Oncology (ASCO) 49: abstract 2619 
Lester J, Coleman R (2005) Bone loss and the aromatase inhibitors. $\mathrm{Br} \mathrm{J}$ Cancer 93(Suppl 1): S16-S22

Mouridsen H, Gershanovich M, Sun Y, Perez-Carrion R, Boni C, Monnier A, Apffelstaedt J, Smith R, Sleeboom HP, Janicke F, Pluzanska A, Dank M, Becquart D, Bapsy P, Salminen E, Snyder R, Lassus M, Verbeek JA, Staffler B, Chaudri-Ross HA, Dugan M (2001) Superior efficacy of letrozole versus tamoxifen as first-line therapy for postmenopausal women with advanced breast cancer: results of a phase III study of the International Letrozole Breast Cancer Group. J Clin Oncol 19: $2596-2606$

Neville-Webbe HL, Evans CA, Coleman RE, Holen I (2006) Mechanisms of the synergistic interaction between the bisphosphonate zoledronic acid and the chemotherapy agent paclitaxel in breast cancer cells in vitro. Tumour Biol 27: $92-103$

Neville-Webbe HL, Rostami-Hodjegan A, Evans CA, Coleman RE, Holen I (2005) Sequence- and schedule-dependent enhancement of zoledronic acid induced apoptosis by doxorubicin in breast and prostate cancer cells. Int J Cancer 13: $364-371$

Oades GM, Senaratne SG, Clarke IA, Kirby RS, Colston KW (2003) Nitrogen containing bisphosphonates induce apoptosis and inhibit the mevalonate pathway, impairing Ras membrane localization in prostate cancer cells. J Urol 170: $246-252$

Ottewell PD, Deux B, Monkkonen H, Cross S, Coleman RE, Clezardin P, Holen I (2008a) Differential effect of doxorubicin and zoledronic acid on intraosseous versus extraosseous breast tumor growth in vivo. Clin Cancer Res 14: $4658-4666$

Ottewell PD, Monkkonen H, Jones M, Lefley DV, Coleman RE, Holen I (2008b) Antitumor effects of doxorubicin followed by zoledronic acid in a mouse model of breast cancer. J Natl Cancer Inst 100: $1167-1178$

Rogers MJ, Gordon S, Benford HL, Coxon FP, Luckman SP, Monkkonen J, Frith JC (2000) Cellular and molecular mechanisms of action of bisphosphonates. Cancer 88: $2961-2978$

Rosen LS, Gordon D, Kaminski M, Howell A, Belch A, Mackey J, Apffelstaedt J, Hussein M, Coleman RE, Reitsma DJ, Seaman JJ, Chen BL, Ambros Y (2001) Zoledronic acid versus pamidronate in the treatment of skeletal metastases in patients with breast cancer or osteolytic lesions of multiple myeloma: a phase III, double blind, comparative trial. Cancer J 7: $377-387$

Shipman CM, Croucher PI, Russell RG, Helfrich MH, Rogers MJ (1998) The bisphosphonate incadronate (YM175) causes apoptosis of human myeloma cells in vitro by inhibiting the mevalonate pathway. Cancer Res 58: $5294-5297$

Thiantanawat A, Long BJ, Brodie AM (2003) Signaling pathways of apoptosis activated by aromatase inhibitors and antiestrogens. Cancer Res 63: $8037-8050$

Winter MC, Holen I, Coleman RE (2008) Exploring the anti-tumour activity of bisphosphonates in early breast cancer. Cancer Treat Rev 34: 453-475 